Dieses Arbeitspapier ist erschienen in:

Strecker, S.; Weinhardt, Ch.: Electronic OTC Trading in the German Wholesale Electricity Market, in: Electronic Commerce and Web Technologies: First International Conference, EC-Web 2000, London, U.K., September 4-6 2000, Proceedings, Hrsg.: Bauknecht, K.; Kumar Madria, S.; Pernul, G., Bd. 1875, Lecture Notes in Computer Science, Hrsg: Goos, G.; Hartmanis, J.; van Leeuwen, J., Berlin et. al.: Springer 2000, S. 280-290.

Last revision: September 112000 


\title{
Electronic OTC Trading in the German Wholesale Electricity Market
}

\author{
Stefan Strecker, Christof Weinhardt* \\ University of Giessen, Information Systems \\ Licher Str. 70, D-35394 Giessen, Germany \\ \{stefan.strecker, christof.weinhardt\}@wirtschaft.uni-giessen.de
}

\begin{abstract}
Recent changes in the German energy policy initiated a deregulation process from a monopolistic to a competitive market, fundamentally changing the market structure, transaction relationships and trading processes. While the mutual exchange of electric energy has been a business activity between vertically integrated utilities for a long time, wholesale electricity trading in an open market only recently started to gain momentum. Electricity becomes a commodity traded at power exchanges and off-exchange on over the counter (OTC) markets. In Germany, the wholesale electricity market is dominated by OTC trading. Trading in OTC markets is usually performed via telephone and facsimile which leads to a limited price transparency, a limited liquidity, an ex ante restricted number of potential market partners and, last but not least, substantial transaction costs. Market participants are therefore searching for new trading mechanisms to circumvent the problems of the current trading processes. The electronization of trading activities promises to reduce the disadvantages of current OTC trading processes through the automation of tasks within the transaction chain. In this context, electronic markets for electricity trading are coordination mechanisms for the market exchange of electricity and electricity derivatives, i. e., a virtual market place where supply and demand meet and trade. An important feature of electronic markets is an automated dynamic pricing which is currently not supported by electronic markets available for electricity trading in the German wholesale market. A concept for an Electronic Electricity Trading System is therefore proposed with a main focus on automated price discovery.
\end{abstract}

\section{Introduction to the German Electricity Markets}

The German Energy Act of 29 April 1998 fundamentally changed the policy for the German energy sector. Following the EU directive 96/92/EC, the new energy legislation breaks up the regulated monopoly and transforms the electric utility industry into a competitive electric power industry [1, p. 14].

\footnotetext{
* The research presented in this paper is funded by the Deutsche Forschungsgemeinschaft (DFG) under project no. WE 1436/4-1. We would like to thank the four anonymous referees for their valuable suggestions and helpful comments. The authors are responsible for all remaining deficiencies.
} 
For more than 100 years, electric energy supply was deemed to be a sector where competition does not achieve the objectives of energy policy makers, i. e., a reasonably priced and secure supply. The German energy policy therefore accepted a regulated monopoly and explicitly excepted exclusive, vertical concession agreements between municipalities and utilities as well as horizontal, interutility demarcation agreements from anti-trust law. This policy led to closed supply areas in Germany prohibiting competition among local, regional and nation-wide utilities. The Energy Act of April 1998 changed this policy radically. Concession and demarcation contracts are now prohibited by antitrust provisions which results in the right to freely choose a supplier. Unbundling of generation, transmission, distribution and trading is enforced whereas only the "wires" business, i. e., the transmission and distribution lines, remains a regulated monopoly due to its natural monopoly characteristics [2, p. 19]. Access to the transmission and distribution lines, i. e., to the grid, must be granted to third parties by the respective grid operator according to an association agreement. As a consequence to the new energy policy, competition was introduced in the generation and trading business [3]. Germany has the largest net electricity demand (483 TWh in 1998) and, hence, the largest market volume in Europe, created by nearly 43 million small-size (mainly private households), and 295,000 medium-size to large-scale (industrial) consumers [4, p. 39]. The size of the market is numbered on 60 billion Euro [5] and the expected overall trading volume (physical and financial) exceeds every other market in Europe by an estimated total of 5 to 10 times the demand, i. e., between 2,415 and 4,830 TWh. Given these figures, electricity trading clearly marks the most prominent effect of the deregulation process.

To discuss the chances for the automation of trading activities in the German electricity market, we describe the commoditization process as a consequence to the deregulation of the German energy policy (section 2). Then, we visualize the changes in the market structure to demonstrate the impact on the trading process (section 3). By describing the current status of electricity trading in Germany (section 4), we motivate a need for electronic markets as coordination mechanisms for the market exchange of electricity and electricity derivatives (section 5). The deficits of existing electronic markets for OTC trading in Germany (section 6) serve as a starting point for our concept for an electronic market for electricity trading (section 7 ). The concluding section briefly summarizes the research layed out in this paper.

\section{Commoditization of Electricity in Germany}

Even though the mutual exchange of electric energy has been a business activity between vertically integrated utilities in Europe for a long time, wholesale electricity trading in an open market only recently started to gain momentum. ${ }^{1}$

${ }^{1}$ Electricity trading is the process of purchase, sale and mediation of electricity and financial derivatives based on electricity, independent of generation assets, transmission and distribution lines [6]. 
The deregulation in Germany initiated a commoditization process, i. e., electric energy becomes a tradable, negotiable entity, valued by price signals emerging through negotiations between supply and demand. Yet, electric energy differs significantly from other commodities like grain or metals: Electricity is a non-storable, conduction-bound commodity with unique physical charateristics. Trading electricity therefore requires market participants to obey the economic and physical constraints but also compels specific trading mechanisms. Specifically, contracts for the delivery of electric energy contain additional negotiable terms such as load, delivery period, delivery time, maturity, etc. By combining various contract terms, distinguishable products emerge and become tradable. Historically, the commoditization process perceptible started in 1999 when price indices were freely published on the World Wide Web (WWW). Power traders and power brokers started to use the Internet as a media to indicate prices. Grid operators communicated prices for access to their grid using the Internet. WWW-sites addressing retail customers appeared in the second half of 1999 . Electronic market places are common means to facilitate wholesale trading in liberalized markets. Last but not least, power exchanges use Internet services for order entry, order routing and deal settlement.

\section{The Impact of Market Structure on Electricity Trading}

Before the deregulation in 1998, the market structure was characterized by a high degree of concentration which led to unique, directed supply chains and a hierarchical market structure with simple transaction relationships: the eight nation-wide utilities generated 80 per cent of the total production in Germany and supplied 33 per cent of the demand to end consumers (mostly large-scale industrial consumers). 80 regional utilities generated 9 per cent of the total production and supplied 36 per cent of the end consumer demand while the majority of 900 local and municipal utilities generated 11 per cent of electric energy in Germany and supplied 31 per cent of the end consumer demand. A similiarly high degree of concentration exists in the "wires" business [7, pp. 242, 270]. As depicted in Fig. 1, today, the German electricity market has a completely different structure. Although a noticeable degree of concentration in the generation and transportation business still remains, a major structural change runs through the deregulated power industry. Primarily, new participants enter the market, i. e., new institutions such as power exchanges and new intermediaries such as wholesale broker affect the way, the electricity business is carried out. The number of potential transaction relationships increased in comparison to the monopolistic structure and, hence, the complexity and risk of conducting business in the electricity industry have grown significantly.

Trading processes have to be differentiated with respect to two market segments: the retail and the wholesale market. Because a common definition for either market has not been established yet, we briefly define retail as well as wholesale electricity trading. 


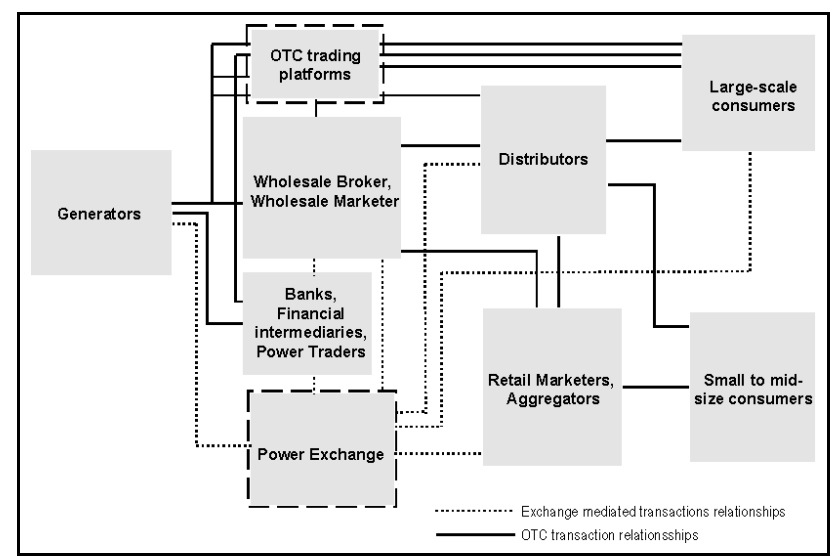

Fig. 1. Market structure and transaction relationships in the competitive German electricity market

Retail electricity trading is conducted at the level of distribution lines (in Germany $110 \mathrm{kV}$ and lower) with reseller-to-end consumer transaction relationships. Market participants in the retail market are small- to mid-size end consumers, typically private households, as well as small and medium enterprises with an electricity consumption, that does not allow them to manage their own energy contract portfolio. A typical contract for electricity delivery in the retail market covers electric energy plus affiliated services like maintenance, metering, energy and load management. Wholesale electricity trading, on the other hand, denotes electricity trading at the level of transmission lines (in Germany $380 \mathrm{kV}$, sometimes $220 \mathrm{kV}$ ) with transaction relationships between generators, intermediaries and large-scale industrial consumers as depicted in Fig. 1. A typical wholesale transaction covers pure energy without affiliated services. Furthermore, wholesale trading requires each market participant to manage and control his own energy contract portfolio, i. e., each wholesale market participant ensures that the portfolio meets his consumption and delivery needs. In the further discussion, we will concentrate on the wholesale market.

\section{The Status Quo of Electricity Trading in Germany}

The German wholesale electricity market is dominated by OTC trading. Only a few market participants trade at foreign power exchanges. In Germany, the first institutionalized power exchanges are scheduled to start in Leipzig at the Leipzig Power Exchange (LPX) in June 2000 and in Frankfurt at the European Energy Exchange (EEX) in August 2000 with a spot market. Futures markets are planned at the EEX for the fourth quarter of 2000 and at the LPX for the end of 2000. Also, the Amsterdam Power Exchange (APX) started a market in Germany on 3 May 2000. Yet, experiences in deregulated markets show that 
even in the presence of power exchanges the predominant amount of deals (70 to 80 per cent) is contracted over the counter, i. e., off-exchange.

Contracts currently traded in the OTC market span a broad spectrum considering the degree of standardization. Some contracts are almost fully standardized such as contracts for the delivery for a complete day, week or month around the clock or on- and off-peak contracts. Individual portfolio contracts mark the other end of the spectrum. Market participants, often utilities, negotiate on a full coverage of their demand using individualized contracts. In Germany, electricity trading takes currently place in the OTC spot and physical forward markets and, increasingly, in the OTC financial forward markets. In the OTC trading process, market participants currently use telephone and facsimile as primary media to conduct negotiation and to execute deals. OTC transactions are either negotiated directly, i. e., bilaterally over telephone, or indirectly, i. e., brokered by an intermediary. Known limitations of telephone and facsimile are considered to be responsible for various disadvantages in the OTC trading process: limited price transparency and liquidity, an ex ante restricted number of potential contract partners and, hence, substantial transaction costs, among others [8, p. 255]. A demand for new market coordination mechanisms, i. e., new ways to bring supply and demand together, arises to cope with the increasing complexity and to comply with the commodity's and participant's requirements. Electronic markets automate the trading process by an electronic support for tasks in the transaction chain and therefore represent potential solutions towards an electronic electricity trading in the German wholesale power market.

\section{$5 \quad$ Electronic Trading Systems for Electricity Wholesale Trading}

The term "trading system" with respect to electricity trading has no unique meaning and a definition often depends on the perspective of the author. At least, two different meanings of the trading systems have to be differentiated: risk management and trade processing (RMTP) software and electronic markets for electricity trading. RMTP software supports the trading activities of a single market participant, i. e., the front, middle and back office tasks on a trading floor, either for the management of physical (generation, dispatch and scheduling software) or financial trading (risk management software) [9]. In contrast, electronic markets for electricity trading are coordination mechanisms for the market exchange of electricity and electricity derivatives, i. e., a virtual market place where supply and demand meet and trade [10]. Following Picot et. al. [11], electronic electricity markets are computer systems for electronic electricity trading which enable the trade between several, possibly an arbitrary number of, market partipants with electricity and electricity derivatives using information and communication technology (ICT) to automate (parts of) the transaction chain.

A trading or market process consists of a transaction chain of sequential transaction phases. Different phase models have been proposed to capture the 
semantics of trading processes. Schmid suggests different phase models for electronic markets $[12,13]$. Similiar models exist for market processes in securities trading $[14,15]$. Typically, phase models subdivide the market process into four successive transaction phases: the knowledge, bidding, negotiation and settlement phase. In the knowledge or information phase, a market participant searches for quotes, product qualities and contract terms suiting his transaction desire. Assuming a potential deal attracted the participants interest, the specification and transmission of an order to the point of execution takes place in the bidding phase (or orderrouting phase). Once placed in the market, the negotiation over contract terms starts and will possibly end in an agreement (negotiation phase). Subsequently, the contract partners exchange money for the contracted commodity in the settlement phase. The negotiation phase itself consists of three interdependent processes: product matching (or matching of contract terms), counterparty matching and price discovery [16] whereas alternative pricing procedures exist for the price discovery process: ${ }^{2}$ The discovery of prices could either be a manual, requiring human intervention, or an automated, i. e., computerized process. In this respect, dynamic pricing as an umbrella term refers to price discovery mechanisms where a price emerge over time.

Electronic markets differ by the level of automation within the transaction chain and their support for processes in a specific transaction phase [18]. The critical process when automating the transaction chain is the price discovery. A core component of electronic markets are electronic trading systems (ETS) as they automate the price discovery and trade execution process by an electronic support for the bidding and negotiation phase through an automated order routing, price matching and trade execution $[19$, p. 27]. Electronic trading systems are operated by computer exchanges and electronic OTC markets. In the financial markets, electronic off-exchange trading systems are called proprietary trading systems (PTS) or alternative trading systems (ATS) [20]. We link this terminology to electronic markets for electricity trading and separate two groups of electronic trading systems:

- Electronic Electricity Trading Systems (EETS) are alternative trading systems in the OTC electricity markets

- Power Computer Exchanges (PCE) are fully automated and integrated commodity exchanges for electricity trading

\section{Electronic OTC Trading in the German Wholesale Market}

Eight electronic markets are available for wholesale electricity trading in Germany as of 10 March 2000 (see Tab. 1). The markets differ regarding technology, current status and operator type. Existing electronic markets are based on three technologies: Electronic Data Interchange (EDI), W3C standards (HTTP, HTML, etc.), and pure TCP/IP with proprietary client/server technology.

\footnotetext{
${ }^{2}$ According to Domowitz, "enabling this process of price discovery is a basic function of any trading market mechanism" [17].
} 
Table 1. Technology, current status and operator type of existing electronic markets

\begin{tabular}{|c|lc|c|c|c|}
\cline { 2 - 5 } \multicolumn{1}{c|}{} & $\begin{array}{l}\text { Electronic Markets for } \\
\text { Electricity Trading }\end{array}$ & Technology & Current Status & Operator Type \\
\hline \multirow{2}{*}{ Electronic } & NetStrom & pbi powerbroker & W3C & Testing & Consulter \\
OTC & Enron Strommarkt & W3C & Price Indication & Broker \\
Markets & SKM Marketplace & TCP/IP & Price Indication & Marketer \\
& Enron Online & W3C & Transaction & Marketer \\
\hline Power & Nord Pool & EDI & Transaction & Exchange \\
Exchange & APX & W3C & Transaction & Exchange \\
& OMEL & W3C & Transaction & Exchange \\
\hline
\end{tabular}

The current status shows the primary focus of the systems whereas the operator type demonstrates the diversity of market participants interested in electronic (OTC) trading. If we sort the available electronic markets by their support for the transaction phases, a lack of support for the negotiation and settlement phase for OTC transactions becomes apparent (see Tab. 2): ICT is primarily used to support the knowledge and bidding phase. Electronic OTC markets are commonly used within the knowledge phase for price indication and within the bidding phase for posting offers in closed user group extranet systems. Yet, as of today, negotiation and bargaining takes place over telephone. Only two systems offer first approaches to an electronic support for the negotiation phase: Enron Online and SKM Marketplace. Enron Online, a system originating from the liberalized U.S. power markets, offers standardized contracts on a WWW-based electronic market where subscribers are able to post bid and ask offers to conclude a contract with the operating company, Enron. Negotiable contract terms are restricted to price and quantity. SKM Marketplace uses a proprietary client interface to display bid and ask offers entered by SKM brokers. The negotiation phase is supported by an electronic chat system which aims to replace telephone conversations.

Table 2. Support for transaction phases by electronic markets available to German participants

\begin{tabular}{|c|lc|c|c|c|c|}
\cline { 2 - 6 } \multicolumn{1}{c|}{} & Electronic Markets for & Knowledge & Bidding & Negotiation & Settlement \\
\hline \multirow{2}{*}{ Electricity Trading } & NetStrom & $\sqrt{ }$ & $\sqrt{ }$ & & \\
Electronic & pbi powerbroker & $\sqrt{ }$ & $\sqrt{ }$ & & \\
OTC & Enron Strommarkt & $\sqrt{ }$ & $\sqrt{ }$ & & \\
& SKM Marketplace & $\sqrt{ }$ & $\sqrt{ }$ & $(\sqrt{ })$ & \\
& Enron Online & $\sqrt{ }$ & $\sqrt{ }$ & $(\sqrt{ })$ & \\
\hline Power & Nord Pool & $\sqrt{ }$ & $\sqrt{ }$ & $\sqrt{ }$ & $\sqrt{ }$ \\
& APX & $\sqrt{ }$ & $\sqrt{ }$ & $\sqrt{ }$ & $\sqrt{ }$ \\
& OMEL & $\sqrt{ }$ & $\sqrt{ }$ & $\sqrt{ }$ & $\sqrt{ }$ \\
\hline
\end{tabular}


The clearing and settlement of off-exchange contracts is currently not supported by any electronic OTC market. Power computer exchanges, by definition, support the entire transaction chain, i.e., they offer clearing and settlement services not only to exchange but also to OTC transactions. In summary, the automation in existing electronic OTC markets is limited. Only the first two transaction phases are well-supported. The electronic support for the negotiation phase in electronic OTC markets is rudimentary.

\section{A Concept for an Electronic Electricity Trading System}

Our concept aims to combine market microstructure theory and auction theory with electronic markets since the automation of price discovery mechanisms has been discussed in the context of financial markets [21, p. 139] as well as electronic commerce [13, p. 468].

The implementation of an automated dynamic pricing depends on the degree of contract standardization. Highly standardized contracts (e. g. certain electricity forward contracts) with fixed contract terms leave only price and quantity to be negotiated. Price discovery mechanisms for highly standardized contracts are well-known in form of auction mechanisms [22]. The automation of auctions has been shown in computerized stock exchanges, e.g., the system XETRA (eXchange Electronic TRAding) and retail auctions, e.g., ebay.com. Auction mechanisms have also been applied to electricity trading [23].

Semi-standardized contracts differ from standardized products in only a single contract term, e.g. delivery period. A standardized peak product typically covers a constant load of $1 \mathrm{MW}$ from $8 \mathrm{am}$ to $8 \mathrm{pm}$ while a semi-standardized peak may cover $7 \mathrm{am}$ to $9 \mathrm{pm}$. Individualized contracts differ from standardized contracts in two or more contract terms. In fact, individualized contracts may contain arbitrary agreements over an arbitrary number of contract terms. An automated price discovery for non-standardized contracts must therefore enable negotiations over an arbitrary number of contract terms and, hence, renders auction mechanisms which depend on "a well-defined object or contract" [24] inappropriate. Therefore, alternative price discovery mechanisms need to be implemented to electronically support the negotiation phase with non-standardized contracts. Price discovery mechanisms known to work with non-standardized contracts are bulletin board systems, sometimes called "hit and take" markets, where market participants "hit" an offered contract to conclude a deal without re-negotiation of any contract term [18, p. 29]. If a market participant wants to re-negotiate, e.g., on the price, a "hit and chat" market allows market participants to hit a specific offer and re-negotiate contract terms through a chat system, possibly supported by a guided user interface.

Further automation can be achieved by automated negotiations "when the negotiating function is performed by (networked) computers", i. e., "a process in which two intelligent software agents negotiate a solution electronically [...]" [25, p. 263]. Automated negotiations using software agents have been discussed in literature [26] and applied to electricity trading [27]. Besides the actual price dis- 


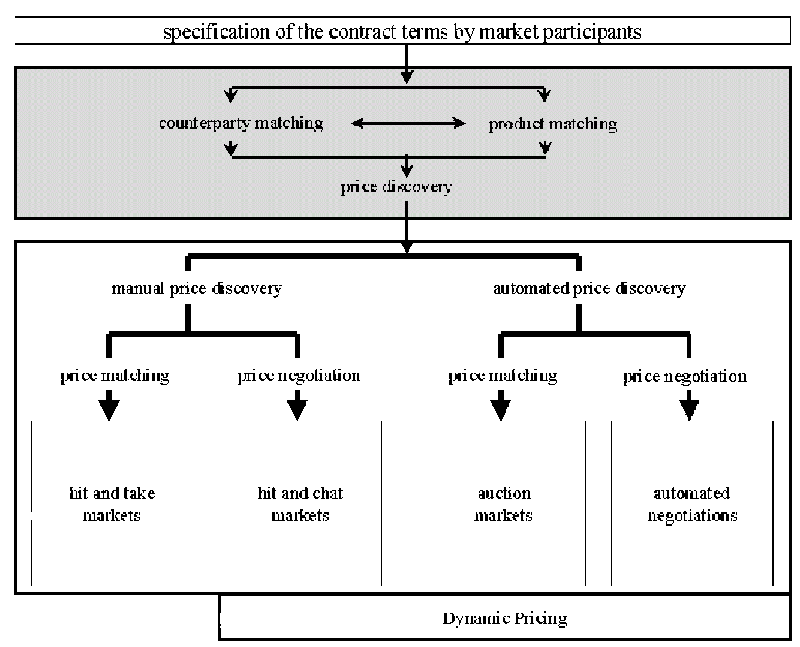

Fig. 2. Market models in ELTRAS

covery mechanisms, the market organization, legal framework, information technology and custom and usances, among others, influence the market efficiency and price quality [28]. A particular combination of (market micro-) structural features (e.g. market transparency: closed or open orderbook; trading frequency: periodically or continuously; price discovery: auction or market maker market) of a specific market constitutes a "market model". A term which originally refered to the market structures, i. e., the rules and regulations, of stock exchanges [29]. Market participants make different demands on market models in different trading situations, i. e., market models must comply with the heterogeneity of market participant's transaction desires. Static market models enjoin a set of concrete structural features and, therefore, meet only predetermined transaction desires. As an extension, dynamic market models enable market participants to choose (from a range of) structural features for each transaction (e.g. bilaterally negotiate an tailor-made contract and use an auction for a highly standardized contract) [30].

Our concept for an EETS, called ELTRAS (Electricity Trading System), approaches standardized as well as non-standardized contracts, i. e., we investigate bulletin board systems, then expand our focus on auction mechanisms (see also [23]) and finally, we will transfer insights from our agent-based bond trading system, AMTRAS (Agent-Mediated Trading System) [16] to ELTRAS (see Fig. 2). Before the latter, we will empirically analyze the market demand for automated negotiations using software agents in the context of electricity trading. ELTRAS aims to verify our working hypothesis that insights into the market structure and trading processes of financial markets can be transferred to electricity markets. Our main focus is on designing dynamic market models and extending them to allow an automation of the negotiation phase in electricity trading. 


\section{Synopsis and Future Research}

In this paper, we argue that OTC trading in the German wholesale electricity market lacks electronic support for the most important transaction phase within the trading process, the negotiation phase. While electricity trading in Germany is dominated by OTC transactions, the full potential for an automated off-exchange trading process is not being exhausted. Concerning the German wholesale electricity market, a lack of electronic trading systems as the vital component of electronic markets has been unfolded, both in exchange and offexchange markets. A concept for an Electronic Electricity Trading Systems was introduced which is based upon our vision of an automated dynamic pricing. Future research will be concerned with the implementation of price discovery mechanisms reflecting the commodity's peculiarities and the market participant's requirements for an Electronic Electricity Trading System. We consider the evaluation of our design by Internet experiments as the final destination in our endeavor.

\section{References}

[1] Meller, E.: Chancen und Risiken der Liberalisierung im Strommarkt. Brennstoff Kraft Wärme 7/8 (1998)

[2] Schmidtchen, D., Bier, C.: Liberalisierte Strommärkte. Mohr Siebeck, Tübingen (1997)

[3] Pfaffenberger, W., Münch, D., Salge, K.: Liberalisierung des Strommarktes in Deutschland. In et. al., H., ed.: Liberalisierung des Energiemarktes. Volume 8 of Schriften des Forschungszentrums Jülich, Reihe Energietechnik / Energy Technology., Jülich, Forschungszentrums Jülich, Zentralbibliothek (1999) 113-147

[4] Bundesministerium für Wirtschaft und Technologie: Energie Daten 1999. On-line at http://www.bmwi.de, Bonn (1999)

[5] Finsterbusch, S.: Die Liberalisierung des Strommarktes nimmt Gestalt an. Frankfurter Allgemeine Zeitung (1999)

[6] Preußer, P.: Stromverkauf an Großkunden. In Weizäcker, C., ed.: Energiehandel und Energiemärkte. Volume 30 of Tagungsberichte des Energiewirtschaftlichen Instituts., München, Energiewirtschaftliches Instituts an der Universität Köln, Oldenbourg (1998) 219-241

[7] Drasdo, P., Drillisch, J., Hensing, I., Kreuzberg, P., Nolden, A., Perner, J., Riechmann, C., Schulz, W., Schuppe, T., Starrmann, F., eds.: Konzentration und Wettbewerb in der deutschen Energiewirtschaft. Volume 52 of Schriften des Energiewirtschaftlichen Instituts an der Universität Köln. Oldenbourg, München et. al. (1998)

[8] Gomber, P., Budimir, M., Kosciankowski, K., Urtheil, R.: Elektronisierung des außerbörslichen Rentenhandels auf Basis von Softwareagenten. In Weinhardt, C., Meyer zu Selhausen, H., Morlock, M., eds.: Informationssysteme in der Finanzwirtschaft. Springer, Heidelberg (1998) 253-267

[9] Frost, J.C.: The Software Acquisition Process. Power Marketers Online Magazine (1999) On-line at http://www.powermarketers.com.

[10] Schmid, B., Lindemann, M.A.: Elements of a Reference Model for Electronic Markets. In Sprague, E., ed.: Proceedings of the 31st Haiwaii International Conference on Systems Sciences (HICSS'98). Number 4 (1998) 193-201 
[11] Picot, A., Bortenlänger, C., Röhrl, H.: The Automation of Capital Markets. Journal of Computer-Mediated Commerce 1 (1995) On-line at http://www.ascusc.org/ jcmc/vol1/issue3/picot.html.

[12] Schmid, B.: Elektronische Märkte - Merkmale, Organisation und Potentiale. In Hermanns, A., Sauter, M., eds.: Managementhandbuch Electronic Commerce: Grundlagen, Strategien, Praxisbeispiele. Vahlen, München (1999)

[13] Schmid, B.: Elektronische Märkte. Wirtschaftsinformatik 35 (1993) 465-480

[14] Gerke, W.: Computerbörse für den Finanzplatz Deutschland. Die Betriebswirtschaft 53 (1993) 725-748

[15] Picot, A., Bortenlänger, C., Röhrl, H.: Börsen im Wandel. Fritz Knapp, Frankfurt am Main (1996)

[16] Weinhardt, C., Gomber, P.: Agent-Mediated Off-Exchange Trading. In Sprague, E., ed.: Proceedings of the 32nd Hawaii International Conference on Systems Sciences (HICSS'99). Number 5 (1999)

[17] Domowitz, I.: Automating the Price Discovery Process: Some International Comparisons and Regulatory Implications. Journal of Financial Services Research (1992) 305-326

[18] Schenk, N.: Informationstechnologie und Börsensysteme. Gabler, Wiesbaden (1997)

[19] Gomber, P.: Elektronische Handelssysteme. Physica, Heidelberg (2000)

[20] Securities and Exchange Commission: Regulation of Exchanges and Alternative Trading Systems, Final Rule, Release No. 34-40760 (1999)

[21] Gerke, W., Rapp, H.W.: Strukturveränderungen im internationalen Börsenwesen. Die Betriebswirtschaft 54 (1994) 5-23

[22] McAfee, R.P., McMillan, J.: Auctions and Bidding. Journal of Economic Literature 25 (1987) 699-738

[23] Zimmerman, R., Thomas, R.J., Gan, D., Murillo-Sachnez, C.: A web-based platform for experimental investigation of electric power auctions. Decision Support Systems 24 (1999) 193-205

[24] Branco, F.: The design of multidimensional auctions. RAND Journal of Economics 28 (1997) 63-81

[25] Beam, C., Segev, A.: Automated negotiations: a survey of the state of the art. Wirtschaftsinformatik 39 (1997) 263-268

[26] Sandholm, T.: Automated Negotiation. Communications of the ACM 42 (1999) 85-85

[27] Maifeld, T., Sheblé, G.B.: Computer Simulation of an Electric Marketplace Using Artificial Adaptive Agents. In: Proceedings of the 1995 Midwest ElectroTechnology Conference. Number 4 (1995) 68-71

[28] O'Hara, M.: Market Microstructure Theory. Blackwell Publisher, Cambridge, Mass. (1997)

[29] Braue, C., Hille, L.: XETRA - Elektronisches Handelssystem am Finanplatz Deutschland. Die Bank (1997) 140-145

[30] Budimir, M., Gomber, P.: Dynamische Marktmodelle im elektronischen Wertpapierhandel. Wirtschaftsinformatik 41 (1999) 218-225 